\title{
Avaliação da Higienização de Vegetais Folhosos em Serviços de Alimentação
}

\author{
Evaluation of the Hygienization of Leafy Vegetables in Food Services \\ Evaluación de la higiene de las hortalizas de hoja en los servicios alimentarios
}

Recebido: 31/05/2021 | Revisado: 09/06/2021 | Aceito: 11/06/2021 | Publicado: 26/06/2021

\author{
Maria Catarine Almeida dos Santos \\ ORCID: https://orcid.org/0000-0001-7034-7083 \\ Universidade Franciscana, Brasil \\ E-mail: almeida.catarine@hotmail.com \\ Patrícia Arruda Scheffer \\ ORCID: https://orcid.org/0000-0002-2377-2930 \\ Universidade Franciscana, Brasil \\ E-mail: patricia.scheffer@ufn.edu.br \\ Fernanda da Rosa Cardoso \\ ORCID: https://orcid.org/0000-0002-4530-4150 \\ Universidade Franciscana, Brasil \\ E-mail: fernanda.cardoso@ufn.edu.br \\ Lidiane Viera Machado \\ ORCID: https://orcid.org/0000-0002-7715-6180 \\ Universidade Federal de Santa Maria, Brasil \\ E-mail: lidiane.smdr@gmail.com \\ Neila Silva Pereira dos Santos Richards \\ ORCID: https://orcid.org/0000-0001-6610-5567 \\ Universidade Federal de Santa Maria, Brasil \\ E-mail: neilarichardsprof@gmail.com \\ Ana Lúcia de Freitas Saccol \\ ORCID: https://orcid.org/0000-0002-1253-8428 \\ Universidade Franciscana, Brasil \\ E-mail: alsaccol@ufn.edu.br
}

\begin{abstract}
Resumo
Para evitar as Doenças Transmitidas por Alimentos (DTA) é de extrema importância implementar as Boas Práticas de Manipulação (BPM) nos serviços de alimentação (SA). Um dos procedimentos das BPM é a higienização das frutas e hortaliças, que deve ser feito com a realização da lavagem dos vegetais em água corrente e com uso de soluções sanitizantes. O objetivo deste estudo foi avaliar o procedimento de higienização de vegetais folhosos. A avaliação da higienização foi realizada nos SA participantes do processo de categorização em Santa Maria - RS. A pesquisa foi realizada de março a outubro de 2019, com visitas de acompanhamento in loco de acadêmicos e auditorias das autoridades sanitárias do município. Foram 45 SA participantes da Categorização, dentre estes, a presente pesquisa foi aplicada em $74,4 \%$. Os alimentos mais frequentemente higienizados foram alface, rúcula, radite e tomate/pepino. Nos SA $65 \%$ utilizavam e $34 \%$ não utilizava nenhum tipo de produto para desinfecção. Nem todas as etapas de lavagem eram realizadas, controladas e registradas. Conclui-se que os procedimentos de higienização eram seguidos conforme a legislação em alguns SA, mas existiam não conformidades que foram obtendo melhorias. Capacitações são fundamentais para o conhecimento das normas e melhorar os processos, mas práticas inadequadas necessitam de mais atenção dos gestores. A higienização realizada correta e completamente, com controle e registro é uma das melhores formas para garantir segurança dos alimentos e evitar DTAs.
\end{abstract}

Palavras-chave: Vegetais folhosos; Higienização; Categorização.

\begin{abstract}
To avoid Foodborne Diseases (DTA) it is extremely important to implement Good Handling Practices (BPM) in food services (SA). One of the BPM procedures is the cleaning of fruits and vegetables, which must be done by washing the vegetables under running water and using sanitizing solutions. The aim of this study was to evaluate the cleaning procedure for leafy vegetables. The hygiene evaluation was carried out in the SA participating in the categorization process in Santa Maria - RS. The survey was carried out from March to October 2019, with on-site follow-up visits by academics and audits by the city's health authorities. There were 45 SA participants in the Categorization, among them, the present research was applied in $74.4 \%$. The most frequently sanitized foods were lettuce, arugula, radite and tomato / cucumber. In SA $65 \%$ used it and 34\% did not use any type of product for disinfection. Not all washing steps were performed, controlled and recorded. It is concluded that the hygiene procedures were followed according to the legislation in some SA, but there were non-conformities that were improving. Training is essential for knowing the rules and improving processes, but inadequate practices need more attention from managers. Hygiene performed correctly and completely, with control and registration is one of the best ways to ensure food safety and avoid DTAs.
\end{abstract}


Keywords: Vegetables of today; Sanitation; Categorization.

\section{Resumen}

Para evitar las Enfermedades Transmitidas por los Alimentos (DTA) es extremadamente importante implementar Buenas Prácticas de Manejo (BPM) en los servicios de alimentos (SA). Uno de los procedimientos de BPM es la limpieza de frutas y verduras, que debe realizarse lavando las verduras con agua corriente y con soluciones desinfectantes. El objetivo de este estudio fue evaluar el procedimiento de limpieza de las hortalizas de hoja. La evaluación de la higiene se llevó a cabo en la SA participando en el proceso de categorización en Santa María - RS. La encuesta se realizó de marzo a octubre de 2019, con seguimiento in situ de los académicos y auditorías de las autoridades de salud del municipio. Hubo 45 SA participantes en la Categorización, entre ellos, la presente investigación se aplicó en 74,4\%. Los alimentos más higienizados fueron lechuga, rúcula, rábano picante y tomate / pepino. En SA el 65\% utilizó y el 34\% no utilizó ningún tipo de producto para la desinfección. No todos los pasos de lavado se realizaron, controlaron y registraron. Se concluye que los procedimientos de higiene se siguieron de acuerdo a la legislación en algunas SA, pero hubo no conformidades que fueron mejorando. La formación es fundamental para conocer las reglas y mejorar los procesos, pero las prácticas inapropiadas necesitan más atención por parte de los directivos. La higiene realizada de manera correcta y completa, con control y registro es una de las mejores formas de garantizar la seguridad alimentaria y evitar DTA.

Palabras clave: Vegetales de hoja; Saneamiento; Categorización.

\section{Introdução}

O aumento da modernização e demais características do público fez o mercado de alimentação coletiva buscar cada vez mais se adequar as legislações. Essas mudanças garantem a qualidade e a segurança dos alimentos, bem como satisfazer a clientela. Além do sabor e aparência dos alimentos, existe também a preocupação nos riscos de contaminação e agravos a saúde que podem ocorrer, como as Doenças Transmitidas por Alimentos (DTAs). Melhorias nos métodos de processamento dos alimentos e a conscientização de todos os envolvidos na cadeia de produção reduz a incidência das DTAs. As DTAs podem causar náuseas, vômitos e/ou diarreia, com febre ou não, e dependendo da situação, pode levar até mesmo a óbito (Boaventura et al., 2017; Van Amson et al., 2006; Carvalho \& Mori, 2017).

Sendo assim é de extrema importância implementar as Boas Práticas de Manipulação (BPM) nos Serviços de Alimentação (SA). As BPM nada mais são do que práticas de higiene que devem ser obedecidas pelos manipuladores, o cuidado vai desde a escolha e compra dos alimentos, até a venda para o consumidor. O principal objetivo das BPM é de evitar e prevenir as DTAs (Brasil, 2004).

Neste contexto, no Brasil as BPM em SA estão regulamentadas por meio da Resolução de Diretoria Colegiada (RDC) $n^{\circ}$ 216/2004 (Brasil, 2004). Segundo o artigo $n^{\circ} 2$ esta RDC pode ser complementada por órgãos de vigilância sanitária municipais, estaduais e distrito federal. Neste sentido destacam-se as legislações estaduais Portaria n 78/2009 (Rio Grande do Sul, 2009) e do Centro de Vigilância Sanitária (CVS) de São Paulo n 5 (São Paulo, 2013).

Dentre os procedimentos para garantir as BPM, citados nas legislações, ressalta-se as adequações nos processos de higienização das frutas e hortaliças, bem como melhorar a capacitação e profissionalismo de todos os envolvidos nesses processos. Para a correta higienização deve-se realizar inicialmente a lavagem dos vegetais, que é a prática mais comum realizada nos SA, entretanto, a eficácia na operação de lavagem deve ser complementada com o uso de soluções sanitizantes, objetivando a redução e ou eliminação de micro-organismos presentes nestes alimentos, sendo um procedimento obrigatório para alimentos que serão consumidos crus (Chaves et al., 2016).

Para completa desinfecção a lavagem deve ser completa, pois podem constituir possíveis fontes de infecção como cistos e oocistos de protozoários e ovos de helmintos. Estas estruturas são capazes de permanecer infectantes por longos períodos em condições adversas, além de serem resistentes à ação do cloro e do ácido acético nas concentrações usadas para sanitização de alimentos. A legislação preconiza o uso de sanitizantes para a higienização e desinfecção para alimentos que serão consumidos crus, os alimentos que não necessitam higienização são as frutas e hortaliças que irão sofrer ação do calor, 
cujas cascas não serão consumidas e os que serão utilizados no preparo de sucos e vitaminas cujas cascas não serão utilizadas no processo (Gonçalves, 2013; Brasil, 2004; Brasil, 2001).

A higienização correta de frutas e hortaliças para ser completa, deve ser feita com a lavagem em água corrente e com ação mecânica, para eliminar sujidades, após, deve ser feita a imersão em produto sanitizante para eliminar bactérias e vírus patogênicos e o enxágue em água corrente para eliminar a presença do produto químico que também poderia causar danos á saúde (Oliveira et al., 2012; Brasil, 2004).

Estudos sobre presença de parasitas e bacterias em hortaliças comprovam a existência de risco à saúde de consumidores quando a higienização não é feita corretamente, já que mostram a presença de coliformes fecais, E.coli e Staphylococcus acima dos parâmetros da legislação. Falhas durante a higienização também permitem que protozoários e bactérias intestinais do homem sejam transmitidos aos alimentos, como cistos de Entamoeba coli e coliformes fecais, podendo causar DTAs por meio de frutas e hortaliças cruas manipuladas sem os cuidados necessários (Oliveira et al., 2013; Paula et al., 2003; Schirmer, Picanço \& Faria, 2019). Neste contexto o objetivo do presente estudo foi avaliar o procedimento de higienização de vegetais folhosos em SA de Santa Maria - RS.

\section{Metodologia}

Este estudo é do tipo descritivo transversal e quantitativo, segundo Gil (2009) e Creswell (2010). A avaliação da higienização dos vegetais folhosos foi realizada nos SA participantes do processo de categorização em Santa Maria - RS. Todos os 45 estabelecimentos participantes foram convidados, os incluídos assinaram o termo de aceite em participação na pesquisa e os excluídos foram os SA que não realizavam a comercialização de vegetais folhosos ou preparações com alimentos que necessitam de higienização.

A pesquisa foi realizada nos meses de março a outubro de 2019, por meio de visitas de acompanhamento in loco pela equipe acadêmica e auditorias realizadas pelas autoridades sanitárias do município. Durante as visitas da equipe acadêmica foram realizadas as seguintes etapas:

- Na primeira etapa ocorreu a observação visual do procedimento de higienização com a descrição completa do procedimento por meio de diário de campo e da planilha de avaliação. Nesta planilha de avaliação, foi descrito o procedimento realizado pelo funcionário do SA, com a determinação do tempo inicial e tempo final do procedimento, tipo de produto utilizado.

- Na segunda etapa foi conduzida uma entrevista face a face com os responsáveis pela higienização dos SA participantes, com a aplicação de um formulário especifico e realização de registro fotográfico dos produtos utilizados para a sanitização.

As auditorias das autoridades sanitárias ocorreram em dois momentos, uma foi denominada $1^{\circ}$ Ciclo de Inspeção da Categorização, no período de março a maio do decorrente ano, e após as visitas acadêmicas e adequações ocorreu o $2^{\circ}$ Ciclo de Inspeção entre agosto a outubro de 2019. Entre os dois ciclos de auditorias foram realizadas capacitações com os gestores e manipuladores de alimentos sobre BPM. As auditorias foram conduzidas por meio de uma Lista de Avaliação especifica da Categorização, que possui uma pontuação de risco em cada item avaliado. Os fiscais sanitários também utilizaram uma ferramenta tecnológica, do tipo aplicativo para sistema androide, a qual gerou automaticamente um relatório com todos os itens avaliados (Brasil, 2013; Saccol et al., 2018).

Neste estudo detalhou-se o item 7.10 "Alimentos consumidos crus, quando aplicável, submetidos a processo de higienização com produtos regularizados e aplicados de forma a evitar a presença de resíduos”. De acordo com Da Cunha et al. (2016) este item pontua da seguinte forma: a classificação da consequência de 1 a 4; em que 4 é a situação que pode levar 
diretamente a uma DTA; 3 a situação que leva a contaminação dos alimentos; 2 situações de contaminação química ou física; e 1 situação que pode favorecer as DTAs. As falhas associadas a surtos de DTA foram agrupadas em quatro tipos e atribuiu a cada um deles o grau de associação entre 1 a 4, que reflete o grau de associação das falhas com a ocorrência de surtos, sendo que o número quatro significa maior associação e um, a menor.

Foi arbitrado o valor de 240 para os itens com maior impacto em surtos de DTA, os demais itens foram alocados em algum ponto da escala, de acordo com a percepção dos especialistas, bem como da classificação da consequência consensuada com os representantes das vigilâncias sanitárias. Essa escala foi definida como Índice de Impacto (IIp). Além do IIp, realizouse uma análise fatorial para reduzir a dimensionalidade dos dados de forma tal que se obtivesse um escore único, que representasse a qualidade do estabelecimento inspecionado, assim os itens considerados mais críticos foram estudados do ponto de vista multivariado. No caso do item 7.10 foi classificado como item pontuado, com criticidade alta, IIp de 240 e carga fatorial de 0,524 , com consequência grau 4 , tornando esse item de grande importância para a determinação da conformidade nos locais avaliados.

Os dados foram tabulados em planilha do Microsoft Excel, e analisados por meio de estatística descritiva simples. Este projeto faz parte de um estudo maior denominado "Implementação da Categorização dos Serviços de alimentação em Santa Maria-RS”, do programa de Pós-Graduação em Ciência e Tecnologia de Alimentos da Universidade Federal de Santa Maria RS, sendo aprovado no Comitê de Ética desta instituição, conforme parecer 2.890.701.

\section{Resultados e Discussão}

De todos os SA (45) que aderiram a Categorização em Santa Maria (RS) dois não necessitam do procedimento de higienização de frutas e hortaliças em virtude do tipo de serviço realizado. A presente pesquisa foi aplicada em uma amostra representativa de 74,4\% (n=32) dos estabelecimentos participantes. Nos demais locais não foi possível observar o procedimento, pois durante a visita acadêmica para coleta de dados a higienização de frutas e hortaliças não estava acontecendo no local.

Os alimentos mais frequentemente higienizados durante a coleta de dados foram alface $(66 \%)$, rúcula (6\%), radite (3\%) e tomate/pepino (3\%). A alface mostra ser uma hortaliça comercializada popularmente, concordando com o estudo de Paula et al. (2003), pois as amostras obtidas foram somente a alface, analisou-se 30 amostras em restaurantes self-service de Niterói quanto à presença de bactérias e parasitas. Segundo Berbari, Paschoalino e Silveira (2001), entre as hortaliças mais vendidas para consumo cru está a alface (Lactuca sativa L) bastante utilizada na confecção de sanduíches, decorações de pratos, saladas, etc.

Na coleta de dados foi verificada que boa parte dos restaurantes participantes não realiza higienização completa e de forma correta nos alimentos (34\% não utiliza sanitizante). Esta é uma atitude de risco à saúde, já que é um procedimento fundamental para evitar surtos de DTAs. Segundo dados do Sistema de Informação de Agravos de Notificação (SINAN) foram registrados um total de 597 surtos em 2018, sendo 15,8\% em restaurantes/padarias e similares ( $\mathrm{n}=6.903-2009$ a 2018). Ainda com dados do SINAN os alimentos mistos e a água causaram as DTAs, na maioria dos casos $(25,5 \%$ e $21,2 \%$, respectivamente). Desses resultados sabe-se que nem todos os surtos são notificados, além disso não é especificado o que poderiam ser os alimentos mistos, podendo ter acontecido contaminação cruzada no preparo ou até mesmo conter frutas e hortaliças cruas, como por exemplo um sanduiche com vegetais crus.

A higienização correta e completa de frutas e hortaliças é muito importante para evitar DTAs, como já foi citado anteriormente no presente estudo, portanto o uso de sanitizantes na desinfecção é imprescindível. São diversos os tipos de produtos para esse fim, variadas formas e princípios ativos, na forma de liquido, pó e pastilhas, bem como cloro ativo, hipoclorito de sódio, dicloroisocianurato, água sanitária para vegetais, dentre outros. 
Neste estudo foi observado que a maior parte dos restaurantes utilizam dicloroisocianurato de sódio (53\%), o mais preocupante é que 34\% não utiliza nenhum tipo de produto para desinfecção, como mostra a Tabela 1.

Tabela 1 - Produto utilizado na higienização de frutas e hortaliças em serviços de alimentação de Santa Maria (RS), 2019.

\begin{tabular}{lcc}
\hline & Produto & n (\%) \\
\hline Água sanitária & $2(6)$ \\
Hipoclorito de sódio & $2(6)$ \\
Dicloroisocianurato de sódio & $17(53)$ \\
Não utiliza & & $11(34)$ \\
& Total & 32 \\
\hline
\end{tabular}

Fonte: Autores.

No estudo de Silva et al. (2003) foram realizados testes de resistência do Escherichia coli O157:H7 à alguns sanitizantes, sendo que se caracterizou como eficaz os que apresentassem 5 ou mais reduções decimais após 30 segundos de contato. Como resultado o dicloroisocianurato de sódio obteve reduções acima de 6,1 e de 6,3 (com 100ppm e 200ppm, respectivamente) e o hipoclorito de sódio obteve reduções acima de 6,3 tanto em concentração de 100ppm quanto de 200ppm. Esses resultados mostram que esses sanitizantes são muito eficazes na desinfecção de frutas e hortaliças, principalmente no caso de E. coli.

Soares e Cantos (2006) estudaram a contaminação existente em hortaliças comercializadas na cidade de Florianópolis, as variedades foram a alface, o agrião e a rúcula, sendo o agrião a hortaliça mais parasitada (70,4\%), seguido das alfaces (60\%) e por último a rúcula (56\%), mesmas hortaliças avaliadas no presente estudo. Por isso a importância de utilizar sanitizantes específicos para higienizar corretamente as hortaliças, favorecendo assim a garantia de um alimento seguro.

Frantz et al. (2008) analisaram as planilhas de registros de 15 Unidades de Alimentação e Nutrição (UAN) e verificaram que apenas 20,31\% realizavam lavagem em água corrente, 60,11\% realizavam lavagem e desinfecção estipulado pela empresa, fazendo a lavagem folha a folha com água corrente, imersão em solução clorada a 200ppm, por 15 a 30 minutos, e imersão em solução de vinagre a $2 \%$, por 10 minutos. Esse procedimento se assemelha aos resultados encontrados no presente estudo, onde a maior parte dos restaurantes utiliza algum tipo de produto para sanitização (Tabela 1) e também realizam lavagem (78\%), medição da solução clorada (56\%) e enxágue $(66 \%)$ (Tabela 2$)$.

Tabela 2 - Procedimentos realizados na higienização de frutas e hortaliças em Serviços de Alimentação de Santa Maria (RS), 2019.

\begin{tabular}{lcccc}
\hline \multicolumn{1}{c}{ Procedimentos } & Sim & Não & NO & Não se aplica \\
\hline Seleção & $27(84)$ & $4(13)$ & $1(3)$ & - \\
Lavagem & $25(78)$ & $7(22)$ & - & - \\
Medida da água & $19(59)$ & $13(41)$ & - & - \\
Controle do tempo & $13(41)$ & $19(59)$ & - & - \\
Medição do produto sanitizante & $18(56)$ & $13(41)$ & - & $1(3)$ \\
Imersão de todos os alimentos ao mesmo tempo & $13(41)$ & $19(59)$ & - & - \\
Imersão completa & $13(41)$ & $19(59)$ & - & - \\
Enxágue & $21(66)$ & $11(34)$ & - & - \\
Existência de planilha de controle & $8(25)$ & $24(75)$ & - & - \\
\hline
\end{tabular}


Resultados em n (\%); NO= não observado. Fonte: Autores.

No estudo de Gonçalves et al. (2013) os sanitizantes utilizados eram hipoclorito de sódio e cloro em pó, tendo também alguns restaurantes que apenas lavavam com água e alguns que utilizavam vinagre. Dentre os resultados de análise parasitológica $80 \%$ das amostras de alface não higienizadas e $20 \%$ das higienizadas apresentaram algum tipo de estrutura parasitária ou sujidade. Esse resultado indica um alto risco para saúde dos consumidores, o que pode ter ocorrido devido erros e falhas no processo de desinfecção. Deve haver muito cuidado e controle, não apenas utilizar os sanitizantes, mas realizar todos os procedimentos corretamente.

$\mathrm{Na}$ tabela 2 foram analisados os procedimentos realizados nos SA e como resultado grande maioria dos estabelecimentos realiza seleção dos alimentos, o que mostra preocupação com a qualidade do alimento a ser servido, onde se retira o que não esta com aparência ou odor bom, mesmo sabendo que o alimento passará pelo processo de desinfecção. Em apenas um dos estabelecimentos não foi possível observar a seleção, pois foi realizada antes da visita acadêmica.

Sobre a lavagem em água corrente $78 \%$ dos restaurantes realizam essa etapa, a qual mesmo que exista a higienização com produto sanitizante é essencial, pois somente a ação mecânica retira os ovos de larvas que possam estar nos alimentos. A medida da água para a imersão dos alimentos em produto sanitizante é realizado em $59 \%$ dos locais, podendo isso ser prejudicial no resultado final, já que $41 \%$ não tem controle da medida da água. Sem esses controles pode acontecer contaminação química, no caso de pouca quantidade de água e grande quantidade de produto, ou até mesmo uma desinfecção incompleta quando é colocada muita água para pouca quantidade de produto.

Foi observado que mais da metade dos SA realizava a medida da água para a imersão em solução clorada e a maioria dos restaurantes realizava a medição da água com uma marca em um utensílio, uma bacia de higienização. A medição correta da água e do produto sanitizante é de suma importância, pois é a quantidade certa de produto, bem como a quantidade certa de água, que irão realizar a desinfecção completa dos alimentos. Apenas um dos locais não necessitava de medição, pois utilizava sanitizante em forma de pastilha. A medida era realizada pelo próprio medidor do produto na maioria dos locais, mas em alguns lugares utilizavam seringa, colher ou a tampa do produto (Tabela 2).

Uma caraterística importante também é sobre a imersão dos alimentos ao mesmo tempo na solução clorada, devendo ser criterioso esse processo, para que todos os alimentos permaneçam pelo mesmo período de tempo necessário para a desinfecção completa. Mais da metade dos SAs não realizavam imersão de vários alimentos ao mesmo tempo, colocando os alimentos aos poucos durante a lavagem. Ainda 56\% tinham o cuidado de manter todos os alimentos imersos por completo, questão importante também para que todas as partes dos alimentos estejam em contato com o produto. Essas características são de suma importância ao higienizar frutas e hortaliças, garantindo com isso a realização correta do procedimento.

A realização de enxágue após a lavagem e após a imersão em solução clorada é essencial para completar a higienização, de forma a retirar o produto sanitizante por completo e evitar a contaminação química. Nos restaurantes analisados grande parte realizava enxágue (Tabela 2).

Além de todas as etapas de higienização e desinfecção de frutas e hortaliças é importante manter um controle destes procedimentos para garantir que seja padronizado e realizado rotineiramente. Nos locais observados durante a coleta de dados apenas $25 \%$ possui planilha de controle do processo de higienização. No estudo de Frantz et al. (2008) o objetivo foi avaliar os registros de controle dos processos de UANs na região sul do Brasil, como resultado mais de 60\% dos registros de hortifrutigranjeiros demonstraram adequação ao método preconizado pela empresa para higienização e somados a esses, cerca de $20 \%$ dos registros demonstraram a utilização de solução clorada.

No estudo de Fernández et al. (2018) foi observado que 25\% dos manipuladores lavam frutas e legumes de acordo com as diretrizes de segurança. Isso se assemelha ao presente estudo, em que nem todos os procedimentos para a correta 
higienização era realizado nos restaurantes analisados, tornando a higienização incompleta e não garantindo uma alimentação segura.

O controle do tempo de desinfecção é fundamental para a desinfecção completa, pois devem ser seguidas as orientações dos fabricantes, não deixando ultrapassar o tempo, mas também deixando o tempo mínimo para ação do produto, $59 \%$ dos restaurantes não controla o tempo e somente $41 \%$ faz esse controle. O tempo médio observado durante as coletas foi de 16 minutos, o tempo mínimo foi de 6 minutos e o maior tempo foi de 33 minutos, o controle do tempo era monitorado por meio de relógio na parede, em 12 SA, e dois utilizavam cronômetro. A necessidade de controlar o tempo durante a imersão em solução clorada é fundamental para garantir um alimento livre de contaminantes como bactérias e parasitas e ainda livre de contaminação química.

Segundo Frantz et al. (2008) os métodos recomendados de lavagem e desinfecção de hortifruti diferem de autor para autor, em seu estudo mais da metade dos alimentos permaneceu por mais de 15 minutos em solução clorada e $45,81 \%$ por 15 minutos, esses juntos totalizaram $97,36 \%$ do tempo de cloração utilizado, apenas 2,65\% dos hortifruti foram clorados inadequadamente.

Sabe-se que a Capacitação em Boas Práticas de Manipulação em Serviços de Alimentação é uma das exigências da vigilância sanitária, pois isso é de suma importância para garantir a manipulação segura dos alimentos, evitar a contaminação e possíveis surtos de DTAs. Na tabela 3 se observa que 34\% dos restaurantes possuíam manipuladores responsáveis pela higienização de frutas e hortaliças com capacitação realizada a menos de um ano, 31\% com capacitação a mais de um ano e $33 \%$ não eram capacitados.

Tabela 3 - Realização de Capacitação sobre higienização de frutas e hortaliças em Serviços de Alimentação de Santa Maria (RS), 2019.

\begin{tabular}{ll}
\hline Capacitado & n (\%) \\
\hline Não & $10(33)$ \\
Sim $<1$ ano & $11(34)$ \\
Sim $>1$ ano & $10(31)$ \\
Não soube responder & $1(3)$ \\
Total & 32 \\
\hline
\end{tabular}

Fonte: Autores.

No entanto no estudo de Da Cunha et al. (2018) o fato de todos os manipuladores de alimentos serem treinados para executar corretamente as práticas não foi associado ao desempenho da segurança alimentar. Não está completamente claro o papel do treinamento nas atitudes e práticas dos manipuladores de alimentos, sendo observado que o treinamento pode melhorar o conhecimento, mas não está associada às atitudes e práticas dos manipuladores de alimentos. Para Melo e colaboradores (2020), as boas práticas na manipulação de alimentos é uma estratégia para que ocorra a produção de alimentos aptos para o consumo humano.

Silva et al. (2015) realizaram em seu estudo a lista de verificação em duas UANs em Vitória/ES que mostrou que na Unidade 2 não havia nenhum registro de treinamento de manipuladores de alimentos e na Unidade 1 havia inadequação quanto aos registros de treinamento dos programas de capacitação dos manipuladores em boas práticas. O presente estudo obteve um resultado de $33 \%$ dos manipuladores de alimentos não capacitados e $65 \%$ com capacitação de mais ou menos um ano. Comparado ao estudo de Silva et al. (2015), isso mostra que a realização de capacitação dos manipuladores e a existência de registro não tem sido fator utilizado nos SA para garantia da segurança dos alimentos. 
Na Tabela 4 observou-se que durante a realização da Categorização houve melhorias no processo de higienização de frutas e hortaliças nos SA analisados. Na primeira intervenção havia 58\% dos SA em conformidade com as legislações de BPM, de acordo com as autoridades sanitárias, e na segunda intervenção esse número aumentou para 78\%. Este resultado indica os itens que antes não eram cumpridos ou não estavam conforme a legislação, após as capacitações e orientações acadêmicas, sofreram mudanças e adequações.

No estudo de Stangarlin-Fidri et al (2016) os resultados foram semelhantes ao estudo em questão, foi realizado um check list inicial, após foi realizada uma intervenção por meio de capacitações sistemáticas e um novo check list. Como resultado se obteve $77 \%$ de SA adequados antes da intervenção e $88 \%$ adequados após. Isso indica que, após a intervenção sistemática, houve melhorias significativas nos serviços de nutrição hospitalar envolvidos no estudo, tanto na avaliação dos auditores internos como na avaliação dos auditores externos.

Tabela 4 - Comparação do nível de adequação quanto a higienização de frutas e hortaliças nas inspeções das autoridades sanitárias no primeiro e segundo ciclo e nas visitas acadêmicas, Santa Maria, RS, 2019.

\begin{tabular}{|c|c|c|c|c|c|c|}
\hline \multirow[t]{2}{*}{ Item da Categorização } & \multicolumn{2}{|l|}{$1^{\circ}$ Ciclo } & \multicolumn{2}{|c|}{$\begin{array}{l}\text { Avaliação } \\
\text { acadêmica }\end{array}$} & \multicolumn{2}{|l|}{$2^{\circ}$ Ciclo } \\
\hline & $\mathrm{C}$ & $\mathrm{NC}$ & $\mathrm{C}$ & $\mathrm{NC}$ & $\mathrm{C}$ & $\mathrm{NC}$ \\
\hline $\begin{array}{l}\text { 7.10 Alimentos consumidos crus, } \\
\text { quando aplicável, submetidos a } \\
\text { processo de higienização com produtos } \\
\text { regularizados e aplicados de forma a } \\
\text { evitar a presença de resíduos." }\end{array}$ & $25(58)$ & $18(42)$ & $21(65)$ & $11(35)$ & $34(79)$ & $9(21)$ \\
\hline
\end{tabular}

Resultados em n(\%); C= conforme; $\mathrm{NC}=$ não conforme. Fonte: Autores.

Lopes et al. (2015) classificaram o risco sanitário relacionado à higiene, manipulação e armazenamento de alimentos em 29 escolas municipais de Bayeux. Encontraram que em 51,7\% dos SA as verduras eram higienizadas apenas com água corrente, não sendo utilizado nenhum sanitizante. Semelhantemente ao presente estudo que, de acordo com o item 7.10 da lista de verificação, houve menor conformidade no primeiro ciclo e maior conformidade no segundo ciclo, como mostra a Tabela 4. Conforme a avaliação acadêmica mais da metade dos SA utilizavam produtos para sanitização, tornando conforme o procedimento de higienização de frutas e hortaliças no item 7.10, concordando com a avaliação das autoridades sanitárias.

Neste estudo a importância de realizar a higienização de frutas e hortaliças corretamente, bem como realizar os procedimentos de manipulação de alimentos de forma adequada se evidencia, mostrando o quanto é importante seguir corretamente a legislação a fim de favorecer a segurança dos alimentos. A Tabela 4 confirma a grande necessidade de melhorar os procedimentos e de aplicar check lists e capacitações em SA, com intuito de buscar e realizar correções que proporcionem qualidade sanitária.

\section{Conclusão}

Existe ainda a necessidade da realização de mais projetos como a Categorização dos Serviços de Alimentação para proporcionar mais segurança dos alimentos e melhorar os procedimentos de higienização, que se mostrou em conformidade, mas com muitas falhas. A higienização de folhosos realizada de forma correta e completa, com controle e registro é uma das melhores formas para favorecer segurança dos alimentos e evitar DTAs. 
Com isso pode-se concluir que os procedimentos de higienização de vegetais folhosos nos SA avaliados seguiam alguns dos procedimentos recomendados pela legislação, mas existiam muitas inconformidades que ao longo da realização do projeto foram obtendo melhorias.

Capacitações para manipuladores de alimentos são fundamentais para o conhecimento das normas e melhorar os processos para segurança dos alimentos, mesmo assim as práticas inadequadas necessitam de mais atenção dos gestores, a fim de mudar hábitos inadequados durante a manipulação de alimentos. Para futuros trabalhos, sugere-se maiores iniciativas institucionais para aprofundamento sobre o tema proposto por esta pesquisa.

\section{Referências}

Berbari, S. A. G., Paschoalino, J. E., \& Silveira, N. F. A. (2001). Efeito do Cloro na Água de Lavagem para Desinfecção de Alface Minimamente Processada. Ciência e Tecnologia de Alimentos, 21(2), 197-201. https://doi.org/10.1590/s0101-20612001000200014

Boaventura, Luara Thabata Alves Frades, Liliane Pereira, Weber, Márcia Lopes, Pinto, B. O. S. (2017). Conhecimento de manipuladores de alimentos sobre higiene pessoal e boas práticas na produção de alimentos. Revista Univap, 23, 26-33.

Brasil (2013). Agência Nacional de Vigilância Sanitária (ANVISA). Categorização dos serviços de alimentação: material de apoio para serviços de alimentação. Brasília

Brasil (2001). Ministério da Saúde Agência Nacional de Vigilância Sanitária (ANVISA). Resolução da Diretoria Colegiada (RDC) nº 12, de 02 de janeiro de 2001. Aprova o Regulamento Técnico sobre Padrões Microbiológicos para Alimentos. Diário Oficial da União. Brasília.

Brasil (2004). Ministério da Saúde. Agência Nacional de Vigilância Sanitária (ANVISA). Resolução da Diretoria Colegiada (RDC) nº 216, de 15 de setembro de 2004 dispõe sobre Regulamento Técnico de Boas Práticas para Serviços de Alimentação. Diário Oficial da União. Brasília.

Carvalho, S. J. J. de, \& Mori, E. (2017). A importância das boas práticas de manipulação dos alimentos em restaurantes: revisão integrativa da literatura. Revista E-Ciência, 5(2), 108-115.

Chaves, Q. da S., Silva, T. C., Sá, R. L., \& Fortuna, J. L. (2016). Avaliação De Métodos Para Higienização De Alface (Lactuca Sativa L. Var Crispa) Evaluation Of Methods For Sanitation Lettuce https:/docplayer.com.br/53070113-Avaliacao-de-metodos-para-higienizacao-de-alface-lactuca-sativa-1-varcrispa-evaluation-of-methods-for-sanitation-lettuce.html

Creswell, J. W (2010). Projeto de Pesquisa: métodos qualitativo, quantitativo e misto. 3 ed. Porto Alegre: Artmed.

Cunha, Diogo T., Saccol, A. L. d. F., Tondo, E. C., de Oliveira, A. B. A., Ginani, V. C., Araújo, C. V., Lima, T. A. S., de Castro, A. K. F., \& Stedefeldt, E. (2016). Inspection score and grading system for food services in Brazil: The results of a food safety strategy to reduce the risk of foodborne diseases during the 2014 FIFA World Cup. Frontiers in Microbiology, 7(APR), 1-10. https://doi.org/10.3389/fmicb.2016.00614

Cunha, Diogo Thimoteo, de Rosso, V. V., \& Stedefeldt, E. (2018). Food safety performance and risk of food services from different natures and the role of nutritionist as food safety leader. Ciencia e Saude Coletiva, 23(12), 4033-4042. https://doi.org/10.1590/1413-812320182312.21042016

Fernández, N., Cabral de Bejarano, S., Estigarribia, G., Ortiz, A., \& Ríos, P. (2018). Condiciones higiénico-sanitarias basadas en las cinco claves de la OMS de los servicios de alimentación de hospitales del departamento de Caaguazú, Paraguay. Memorias Del Instituto de Investigaciones En Ciencias de La Salud, 16(2), 21-31. https://doi.org/10.18004/mem.iics/1812-9528/2018.016(02)21-031

Frantz, C. B., Bender, B., Oliveira, A. B., \& Tondo, E. C. (2008). Avaliaçao de registros de processos de quinze unidades de alimentação e nutrição. Alimentos e Nutrição Araraquara, 19(2), 167-175. http://serv-bib.fcfar.unesp.br/seer/index.php/alimentos/article/view/230/225

Gil, A. C. (2010). Métodos e técnicas de pesquisa social. 6 ed. São Paulo: Atlas.

Lopes, A. C. de C., Pinto, H. R. F., Costa, D. C. I. de O., Mascarenhas, R. de J., \& Aquino, J. de S. (2015). Avaliação das Boas Práticas em unidades de alimentação e nutrição de escolas públicas do município de Bayeux, PB, Brasil. Ciencia e Saude Coletiva, 20(7), 2267-2275. https://doi.org/10.1590/141381232015207.15162014

Melo, M. T. S. M., Santos, G. M. dos, Macêdo, M. C. F., Silva, B. L. dos S., Ripardo, S. R. P., Torres, B. L. M., Moura, A. C. C., Nunes, I. F. de O. C., Barreto, S. C. S., Paz, S. M. R. S. da, \& Carvalho, C. M. R. G. de. (2020). Segurança sanitária na produção de refeições em restaurantes de um mercado público no nordeste brasileiro. Research, Society and Development, 9 (12), e2191210481. https://doi.org/10.33448/rsd-v9i12.10481

Müller Gonçalves, R., Regina Pavan da Silva, S., \& Stobbe, N. S. (2013). Frequência De Parasitos Em Alfaces (Lactuca Sativa) Consumidas Em Restaurantes Self-Service De Porto Alegre, Rio Grande Do Sul, Brasil. Rev Patol Trop, 42(3). https://doi.org/10.5216/rpt.v42i3.26926

Oliveira, A. B. A; Ritter, A. C.; Tondo, E. C; Cardoso, M. I.(2012). Comparison of Different Washing and Disinfection Protocols Used by Food Services in Southern Brazil for Lettuce. Food and Nutrition Sciences, n. 3, p 28-33.

Oliveira, A. B. A., Capalonga, R., Silveira, J. T., Tondo, E. C., \& Cardoso, M. R. de I. (2013). Evaluation of the presence of hygienic and sanitary indicator microorganisms in food served in public schools in Porto Alegre, Brazil. Ciencia e Saude Coletiva, 18(4), 955-962. https://doi.org/10.1590/s141381232013000400007

Paula, P., Rodrigues, P. S. dos S., Tórtora, J. C. de O., Uchôa, C. M. A., \& Farage, S. (2003). Contaminação microbiológica e parasitológica em alfaces (Lactuca sativa) de restaurantes self-service, de Niterói, RJ. Revista Da Sociedade Brasileira de Medicina Tropical, 36(4), 535-537. https://doi.org/10.1590/s0037-86822003000400019 
Research, Society and Development, v. 10, n. 7, e38410716680, 2021

(CC BY 4.0) | ISSN 2525-3409 | DOI: http://dx.doi.org/10.33448/rsd-v10i7.16680

Rio Grande Do Sul (2009). Secretaria da Saúde. Portaria no 78 de 28 de janeiro de 2009. Aprova a Lista de Verificação em Boas Práticas para Serviços de Alimentação, aprova Normas para Cursos de Capacitação em Boas Práticas para Serviços de Alimentação e dá outras providências. Diário Oficial da União. Porto Alegre.

Saccol, A.L.F; Richards, N. S. P. S; Machado, L.; Pereira, G. S. (2018). Cartilha para Categorização dos Serviços de Alimentação de Santa Maria - RS.

São Paulo (2013). Secretaria de Estado da Saúde. Centro de vigilância Sanitária (CVS). Portaria CVS 5, de 09 de abril de 2013. Aprova o regulamento técnico sobre boas práticas para estabelecimentos comerciais de alimentos e para serviços de alimentação. Diário Oficial da União. São Paulo.

Schirmer, M., Picanço, N. F. M., \& de Faria, R. A. P. G. (2019). Importance of training in ensuring the hygiene-sanitary quality of lettuce salads served in nursery schools. Brazilian Journal of Food Technology, 22, 2018282. https://doi.org/10.1590/1981-6723.28218

Silva, N. da, Silveira, N. F. de A., Yokoya, F., \& Okazaki, M. M. (2003). Ocorrência de Escherichia coli 0157:H7 em vegetais e resistência aos agentes de desinfecção de verduras. Ciência e Tecnologia de Alimentos, 23(2), 167-173. https://doi.org/10.1590/s0101-20612003000200011

Soares, B., \& Cantos, G. A. (2006). Detecção de estruturas parasitárias em hortaliças comercializadas na cidade de Florianópolis, SC, Brasil. Revista Brasileira de Ciencias Farmaceuticas/Brazilian Journal of Pharmaceutical Sciences, 42(3), 455-460. https://doi.org/10.1590/S1516-93322006000300015

Stangarlin-Fiori, L., Medeiros, L. B., Serafim, A. L., Bertin, R. L., Medeiros, C. O., \& Hecktheuer, L. H. (2016). Good hygiene practices in hospital nutrition services: The view of internal and external auditors. Food Science and Technology, 36(3), 461-467. https://doi.org/10.1590/1678-457X.00315

Van Amson, G., Haracemiv, S. M. C., \& Masson, M. L. (2006). Levantamento de dados epidemiológicos relativos à ocorrências/ surtos de doenças transmitidas por alimentos (DTAs) no estado do Paraná Brasil, no período de 1978 a 2000. Ciência e Agrotecnologia, 30(6), 1139-1145. https://doi.org/10.1590/s1413-70542006000600016 